\title{
Advances in coronary stent technology: current expectations and new developments
}

\author{
This article was published in the following Dove Press journal: \\ Research Reports in Clinical Cardiology \\ 28 June 2013 \\ Number of times this article has been viewed
}

\author{
William MWilson \\ Nicholas LM Cruden \\ Edinburgh Heart Center, Royal \\ Infirmary of Edinburgh, Edinburgh, \\ United Kingdom
}

Correspondence: Nicholas Cruden

Edinburgh Heart Center, Royal Infirmary of Edinburgh, 5I Little France Crescent, Edinburgh, United Kingdom, EHI6 4SA

Tel +44 I3। 242 । 843

Email nick.cruden@ed.ac.uk

\begin{abstract}
The field of percutaneous coronary intervention has witnessed many advances over the last few decades that have served to make it a safe and effective treatment for patients with angina due to coronary artery disease. Although the development of drug eluting stents has significantly reduced the need for repeat revascularization procedures, in-stent restenosis, stent thrombosis, and an increase in bleeding events related to the prolonged use of dual antiplatelet therapy remain important issues. The quest for the optimal coronary stent continues with numerous recent developments that are designed to further improve clinical outcomes following percutaneous coronary intervention. This review will focus on recent advances in coronary stent technology, including bioabsorbable stents and dedicated bifurcation stents, and discuss developments on the horizon.
\end{abstract}

Keywords: coronary stent, bioabsorbable stent, bifurcation stent

\section{Background}

Balloon angioplasty of the coronary arteries was first developed in the 1970s as an alternative means of revascularization to coronary artery bypass surgery. A major drawback with balloon angioplasty alone was the high rate of abrupt vessel closure resulting from acute arterial recoil and coronary artery dissection. The introduction of bare metal stents (BMS) in the early 1990s revolutionized percutaneous coronary intervention (PCI), and reduced rates of acute vessel closure associated with balloon angioplasty from $>5 \%$ to $<1 \% .{ }^{1}$ With the resultant reduction in periprocedural myocardial infarction and the need for emergency coronary artery bypass surgery, coronary stent implantation rapidly became the standard of care for patients undergoing PCI such that balloon angioplasty alone was reserved for situations where stent insertion could not be achieved or was not practical. Indeed, in 2008 coronary stents were implanted in $>96 \%$ of 800,000 PCI procedures performed in the US. ${ }^{2}$ Although effective at preventing abrupt closure, the introduction of the BMS has led to the emergence of two important complications, namely stent thrombosis (abrupt thrombotic occlusion) and in-stent restenosis (luminal narrowing due to neointimal proliferation). ${ }^{3}$

Stent thrombosis is a rare but serious complication that results in myocardial infarction or sudden death in $>70 \%$ cases. The incidence of stent thrombosis is highest in the first month following stent implantation, reducing thereafter as the stent becomes incorporated in the vessel wall. Factors associated with an increased risk of stent thrombosis include delayed endothelialization, hypersensitivity reactions to drugs or to the polymer coating of the stent, stent malapposition, and significant disruption to the architecture and integrity of the stent scaffold. ${ }^{4}$ In contrast, clinically significant in-stent restenosis usually 
presents within 6-12 months of stent implantation, manifesting more frequently as recurrent angina. Early studies with first generation BMS reported angiographic restenosis rates of $22 \%-32 \%{ }^{5,6}$ Factors associated with in-stent restenosis include longer lesion and stent length, smaller vessel diameter, ostial lesion location, target lesion bifurcation, significant disruption to the architecture or integrity of the stent scaffold, and the presence of diabetes. ${ }^{7,8}$

Evolution of stent scaffold design combined with the local delivery of antiproliferative agents, such as sirolimus, and the concomitant use of dual antiplatelet therapy have reduced, but not abolished, rates of stent thrombosis and restenosis. In a recent large scale randomized trial comparing clinical outcomes at 2 years with two contemporary drug eluting stents (DES), 1\%-2\% of patients experienced a stent thrombosis and $5 \%$ of patients required repeat revascularization for target lesion failure. ${ }^{9}$ Clearly, these two important complications remain as concerns for the interventional cardiologist and continue to drive advances in coronary stent design and technology.

Bleeding events in patients treated with coronary stents are also a major concern. Bleeding is the most common complication following coronary stent implantation and is associated with adverse clinical outcomes. ${ }^{10}$ Predisposing factors include the need for dual antiplatelet therapy, ${ }^{10}$ the concomitant use of anticoagulants for coexisting conditions, and the fact that almost $5 \%$ of patients will undergo major noncardiac surgery in the 12 months following coronary stent implantation. ${ }^{11}$ Besides optimizing pharmacological strategies, ${ }^{12}$ it is hoped that advances in coronary stent technology designed to reduce thrombotic potential and limit the need for dual antiplatelet therapy may lead to a reduction in bleeding events and improved clinical outcomes.

This review will focus on recent developments in coronary stent technology that have been designed to address the issues of stent thrombosis, in-stent restenosis, and the need for prolonged dual antiplatelet therapy.

\section{Stent scaffold structure}

The key concerns in early coronary stent development were restenosis and deliverability. A reduction in stent strut thickness was associated with a lower incidence of periprocedural myocardial infarction ${ }^{13}$ and restenosis, possibly related to less vascular trauma. ${ }^{14}$ Switching from stainless steel to cobalt alloys for balloon expandable stents allowed for thinner stent struts to be employed without compromising radial strength (as used in the Multilink Vision [Abbott Vascular, Santa Clara, CA, USA; strut thickness of $91 \mu \mathrm{m}]$ and Driver
[Medtronic Inc, Minneapolis, MN, USA; strut thickness $81 \mu \mathrm{m}]$ coronary stents which have been demonstrated as comparable platforms). ${ }^{15}$ Thinner stent struts can be less radio-opaque, which compromises angiographic visibility; however, previous attempts to improve radio-opacity using gold markers were associated with higher rates of restenosis. ${ }^{16}$ More recently, a novel alloy comprising stainless steel and platinum has been developed (Element stent [Boston Scientific, Natick, MA, USA]; strut thickness $81 \mu \mathrm{m})$; radial strength is preserved and the platinum allows for increased radio-opacity which facilitates stent positioning within the coronary artery.

Thinner stent struts, along with a lower metal:artery ratio, and the reduction in the number of fixed connectors between cells, have served to enhance flexibility and conformability, facilitating delivery of longer stents even where marked tortuosity or calcification are present. However, previous attempts enhanced deliverability may come at a price, namely a reduction in radial and longitudinal strength, which can predispose to longitudinal deformation. This can manifest as a change in stent length, strut overlap, strut separation, malapposition, or luminal obstruction and may predispose patients to stent thrombosis. ${ }^{17}$ The recently released Promus PREMIER DES (Boston Scientific) was designed specifically to address this issue and incorporates additional connectors at the proximal end of the stent to improve longitudinal integrity without compromising stent flexibility (Figure 1).

\section{Bioabsorbable stent scaffolds}

Theoretically, bioabsorbable stents afford all the benefits of conventional metallic coronary stents by providing a rigid

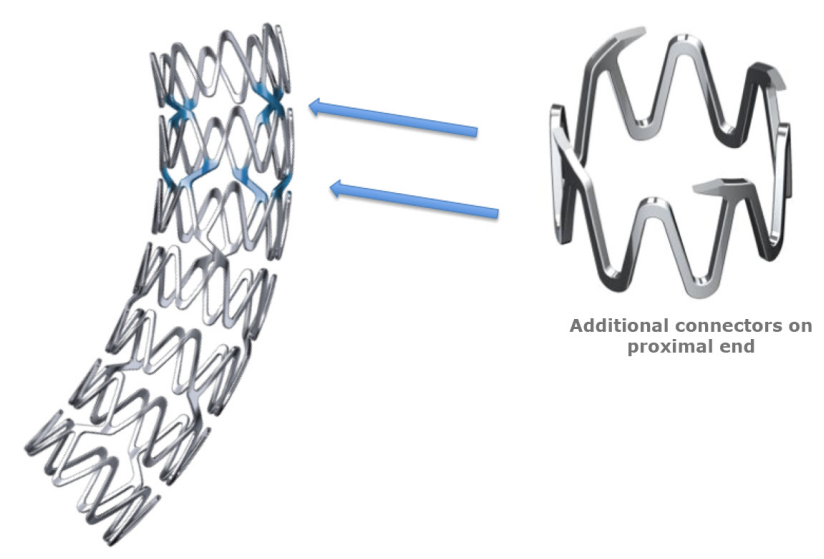

Figure I The Promus PREMIER stent (Boston Scientific, Natick, MA, USA) features a customized stent architecture that includes additional connectors at the proximal end of the stent to improve radial and longitudinal strength.

Notes: The rest of the stent has two connectors to maintain the positive flexibility, conformability, and fracture resistance characteristics of the Element stent series. Image courtesy of Boston Scientific. 
scaffold to prevent vessel recoil and negative remodeling, and a vehicle that permits local drug delivery to inhibit neointimal hypoplasia. Proponents argue that the disappearance of the stent scaffold over time is beneficial for a number of reasons including: recovery of vessel compliance and local endothelial function, avoidance of permanent "jailing" of side branches and "overhang" at coronary ostia, compatibility with subsequent cardiac computed tomography and magnetic resonance imaging (lack of artifact from stent struts), and the ability to undergo subsequent coronary bypass grafting, even at the original site of stent implantation. ${ }^{18}$ Whether these benefits translate into a reduction in the risk of stent thrombosis remains to be determined.

Potential drawbacks of bioabsorbable stents include embolization of a partially degraded stent scaffold, difficulties in delivering or deploying the bulky polymer stents (thicker struts are required to maintain radial force), and the lack of radio-opacity. Care must be taken when implanting bioabsorbable stents to ensure target lesions are adequately prepared as aggressive postdilatation can cause strut fracture and should be avoided. Extensive calcification and marked proximal tortuosity may limit the successful delivery of current generation bioabsorbable stents.

The duration and process of stent resorption also requires careful attention. If resorption is too rapid, recoil may occur and compromise long-term patency. ${ }^{19}$ If resorption is too slow, patients remain exposed to the risk of restenosis and stent thrombosis. As a result, it has been suggested that the optimal duration for the presence of a stent scaffold following balloon dilation of a coronary artery is 6 months. ${ }^{20}$ Table 1 summarizes the potential advantages and disadvantages of bioabsorbable stents. An outline of contemporary bioabsorbable stents is provided in Table 2 .
Constructed from poly-L-lactic acid (PLLA) monofilament with no antiproliferative drug coating, the Igaki-Tamai stent (Kyoto Medical Planning Co, Kyoto, Japan) was the first biodegradable stent to undergo clinical evaluation in humans, and demonstrated comparable clinical outcomes to contemporary BMS..$^{21}$ Unfortunately, delivery and deployment necessitated the use of an $8 \mathrm{~F}$ guiding catheter and prolonged exposure to heated contrast medium, respectively, thus limiting clinical use. A second generation stent, delivered via a $6 \mathrm{~F}$ guide catheter without the need for heat application, is currently undergoing preclinical evaluation.

The bioabsorbable vascular solutions (BVS) everolimus eluting stent (Abbott Vascular) is the first bioabsorbable stent to become commercially available (Figure 2). Made from a bioabsorbable polymer backbone of PLLA with a polymer coating of poly-D,L-lactide that contains and controls the release of the antiproliferative drug, everolimus, it is the first bioabsorbable stent to yield clinical and imaging outcomes comparable to conventional DES implantation. ${ }^{22,23}$ The stent has undergone a series of revisions to address concerns regarding mechanical integrity. Clinical data from the recent ABSORB B study in 101 patients demonstrated late loss and minimal luminal area at 6 months, comparable with current generation everolimus eluting stents. ${ }^{24}$ Complete bioresorption of the implant occurred by 2 years with no compromise of luminal area and restoration of pharmacologic vasomotion at the site of implantation. ${ }^{25}$ The ABSORB II clinical trial, ${ }^{26}$ a randomized head to head comparison with a metallic everolimus eluting stent, is currently ongoing.

The DREAMS bioresorbable stent (Biotronik, Berlin, Germany) is the only fully bioresorbable metallic stent to undergo clinical evaluation in humans. Coated with a bioabsorbable polymer and the antiproliferative drug, paclitaxel,

Table I Bioabsorbable scaffolds (advantages and disadvantages)

\begin{tabular}{|c|c|}
\hline Advantages & Disadvantages \\
\hline $\begin{array}{l}\text { Recovery of normal endothelial function/vasomotion and allowance for late luminal } \\
\text { enlargement and late expansive remodeling }\end{array}$ & Potential embolization of partially degraded material \\
\hline Lack of continuous vessel wall trauma through continuous mechanical loading & $\begin{array}{l}\text { Difficult delivery of bulky stents (thicker stent } \\
\text { struts required to maintain radial force) }\end{array}$ \\
\hline Absence of permanent foreign material within artery wall (reduced thrombotic potential) & Lack of radio-opacity (necessitates radio-opaque \\
\hline Reduced need for prolonged DAPT with lower bleeding risk & markers) \\
\hline Avoidance of permanent jailing of side branches and ostial "overhang" & $\begin{array}{l}\text { More fragile scaffold may limit ability to optimize } \\
\text { stent deployment (eg, postdilatation) }\end{array}$ \\
\hline Reduced artifact with future coronary imaging (CTCA or MRI) & $\begin{array}{l}\text { Acute treatment of side branches may be limited } \\
\text { immediately following stent implantation }\end{array}$ \\
\hline $\begin{array}{l}\text { Future revascularization options preserved (repeat revascularization easier and ability } \\
\text { to graft stented segment maintained) }\end{array}$ & $\begin{array}{l}\text { Control of resorption rate can be unreliable } \\
\text { (predisposing to recoil if too rapid or restenosis } \\
\text { and thrombosis if too slow) }\end{array}$ \\
\hline
\end{tabular}

Abbreviations: CTCA, computed tomographic coronary angiography; DAPT, dual antiplatelet therapy; MRI, magnetic resonance imaging. 
Table 2 Bioabsorbable stents: examples

\begin{tabular}{|c|c|c|}
\hline Stent & Characteristics & Clinical evidence \\
\hline Igaki-Tamai stent & $\begin{array}{l}\text { First stent to undergo clinical evaluation in humans } \\
\text { PLLA monofilament with no drug coating } \\
\text { Requires 8F delivery guide and prolonged exposure } \\
\text { to heated contrast medium } \\
\text { Currently only used in peripheral vessels }\end{array}$ & $\begin{array}{l}50 \text { patients ( } 84 \text { stents) with long-term follow-up } \\
\text { Rates of target vessel revascularization comparable } \\
\text { with BMS (I8\% at } 5 \text { years, } 28 \% \text { at } 10 \text { years) }{ }^{22}\end{array}$ \\
\hline $\begin{array}{l}\text { Bioabsorbable vascular } \\
\text { solutions stent }\end{array}$ & $\begin{array}{l}\text { PLLA backbone with a polymer coating (poly-D,L-lactide) } \\
\text { that contains and controls delivery of everolimus }\end{array}$ & $\begin{array}{l}\text { ABSORB B study: I0I patients, } 6 \text { month results (late } \\
\text { loss, MLA) comparable with current generation } \mathrm{DES}^{24} \\
\text { Randomized head-to-head trial with conventional DES } \\
\text { (Xience) in progress }\end{array}$ \\
\hline IDEAL BDS stent & $\begin{array}{l}\text { Made from salicylic acid derivatives } \\
\text { Releases sirolimus and aspirin to provide antiproliferative } \\
\text { and anti-inflammatory effects }\end{array}$ & $\begin{array}{l}\text { Pilot study demonstrated no acute recoil but } \\
\text { insufficient neointimal suppression } \\
\text { Second generation stent in development }\end{array}$ \\
\hline DREAMS stent & $\begin{array}{l}\text { Magnesium stent with bioabsorbable polymer } \\
\text { and paclitaxel coating }\end{array}$ & $\begin{array}{l}\text { BIOSOLVE-I: Target lesion revascularization } \\
\text { occurred in } 7 \% \text { patients at I year }{ }^{27}\end{array}$ \\
\hline Rezolve stent & $\begin{array}{l}\text { Sirolimus coated radio-opaque stent constructed from a } \\
\text { tyrosine poly(desamino tyrosyl-tyrosine ethyl ester) carbonate }\end{array}$ & Currently undergoing clinical trials (RESTORE) \\
\hline
\end{tabular}

Abbreviations: BMS, bare metal stent; DES, drug eluting stent; MLA, minimum lumen area; PLLA, poly-L-lactic acid.

this magnesium based stent exhibits mechanical properties that are similar to conventional metallic stents, and this permits thinner strut size to facilitate delivery. Modification of the magnesium alloy addressed the issue of early recoil that was observed with the first generation stent. In the recent BIOSOLVE-1 trial, use of the DREAMS stent was associated with low rates of target lesion failure at 6 and 12 months (4\% and 7\%, respectively) with no safety concerns. $^{27}$

Comprised of a polyanhydride ester and salicylic acid, the IDEAL BDS stent (Bioabsorbable Therapeutics, San Jose, CA, USA) is a fully absorbable sirolimus eluting stent that releases salicylic acid and is promoted as possessing both antiproliferative and anti-inflammatory properties. ${ }^{28}$ While a pilot study has confirmed safety with no evidence of recoil,

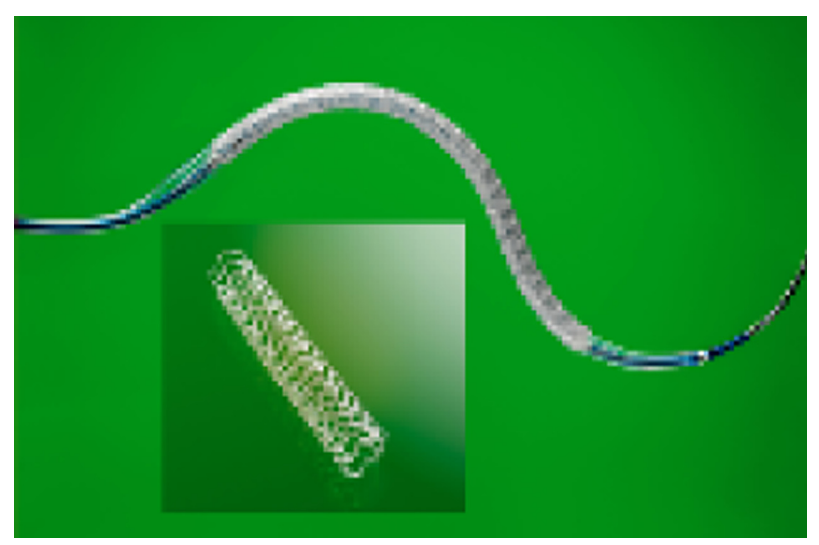

Figure 2 The bioabsorbable vascular solutions everolimus eluting stent (Abbott Vascular, Santa Clara, CA, USA) is made from a bioabsorbable polymer backbone of poly-L-lactic acid with a polymer coating of poly-D,L-lactide that contains and controls the release of the antiproliferative drug, everolimus. insufficient neointimal suppression was an issue. A second generation stent is now in development.

The Rezolve bioabsorbable stent (Reva Medical Inc, San Diego, CA, USA) is a sirolimus coated radio-opaque stent constructed from a tyrosine poly (desamino tyrosyl-tyrosine ethyl ester) carbonate. It is currently undergoing clinical assessment in the RESTORE trial, with plans for a larger clinical study comparing outcomes with a conventional metallic DES already well advanced.

While early results with biodegradable stents show promise, challenges remain in developing a stent that maintains sufficient radial strength for an appropriate duration without overly thick struts, or that can be used as a drug vehicle, and whose degradation does not incite an inflammatory response. The goal is for a healed, normally functioning vessel with no residual foreign material, and no ongoing risk of restenosis or stent thrombosis.

\section{Self-expanding stent scaffolds}

The self-expanding coronary nitinol Wallstent (Boston Scientific) was the first stent used in the coronary circulation, but it had issues with deliverability and high restenosis rates. ${ }^{29}$ This concept was soon abandoned with the arrival of balloon expandable stents. More recently, however, the use of self-expanding scaffolds has been revisited, in particular to tackle bifurcation lesions.

The STENTYS (STENTYS, Paris, France) self-expanding nitinol stent, developed both as a BMS and as a DES coated with a biostable polysulphone polymer eluting paclitaxel, is approved for use in Europe (Figure 3). While its use has been promoted in the setting of bifurcation lesions, ${ }^{30}$ its real 


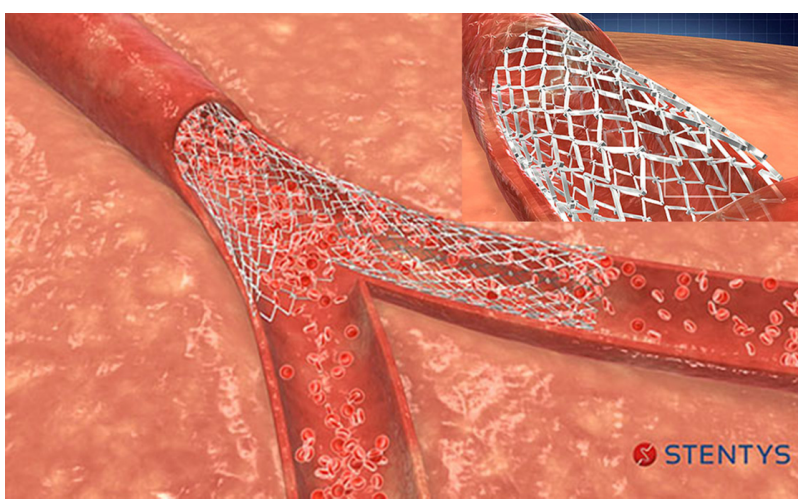

Figure 3 The STENTYS ${ }^{T M}$ (STENTYS, Paris, France) self-expanding nitinol stent, developed as a bare metal stent and a drug eluting stent coated with a biostable polysulphone polymer eluting the antiproliferative agent, paclitaxel.

strength probably lies in the treatment of acute myocardial infarction where vessel sizing due to thrombus and vasoconstriction may be ambiguous. In the recently published APPOSITION II (Randomized Comparison between the STENTYS Self-Expanding coronary Stent and a BalloonExpandable Stent In Acute Myocardial Infarction) study, use of the STENTYS stent was associated with significantly less early strut malapposition $(0.58 \%$ versus $5.46 \%, P<0.001)$ when compared to a conventional BMS. ${ }^{31}$ It remains to be determined whether these benefits will translate into improved longer term clinical outcomes.

Delivered via a 0.014 inch guide wire based platform rather than conventional balloon expandable technology, the Cardiomind Sparrow (Biosensors International, Singapore) is an ultrathin, self-expanding nitinol stent developed for the treatment of small vessels. ${ }^{32}$ Like the STENTYS stent, it has been developed both as a bare metal and drug eluting scaffold, which is coated with a polylactic acid based biodegradable polymer and elutes the antiproliferative agent, sirolimus. ${ }^{33}$ With a strut thickness that is approximately $50 \%$ of conventional DES, radial strength remains a concern but early reports are promising. ${ }^{34}$

\section{Micromesh covered stent}

Aimed primarily at patients presenting with an acute ST elevation myocardial infarction, the MGuard stent (InspireMD, Tel Aviv, Israel) is a novel BMS covered with a polyethylene terephthalate micronet mesh designed to trap thrombus and limit distal embolization. Results from a recent randomized study of 433 patients presenting with acute ST elevation myocardial infarction demonstrated that complete resolution of ST segment elevation occurred more frequently $(57.8 \%$ versus $44.7 \%$ ) and angiographic surrogates of myocardial blood flow improved with the MGuard stent when compared with commercially available BMS. ${ }^{35}$ Data on medium- to long-term clinical outcomes are awaited.

\section{Dedicated bifurcation stents}

The optimal management of percutaneous revascularization involving coronary bifurcation lesions remains to be established. For the majority of bifurcation lesions, a provisional strategy to stent the main vessel and "rescue" the side branch only where perfusion is threatened is generally accepted as the treatment of choice. ${ }^{36-42}$ Where side branch stenting is mandated, controversy remains regarding the optimal technique using conventional stents. The major limitations of conventional stenting techniques for bifurcation lesions include an inability to scaffold the side branch ostium completely, distortion of the main branch stent following side branch dilation, the potential loss of a jailed side branch, and the inability to rewire the side or main branch. ${ }^{39}$ Furthermore, clinical outcomes following stenting of bifurcation lesions remain inferior to clinical outcomes following treatment of nonbifurcation lesions, irrespective of which approach is used. These issues have led to the development of a number of dedicated bifurcation stents. These stents vary widely in the type of material used for construction (nitinol versus various metallic alloys), the method of delivery (balloon expanding versus self-expanding), the presence of antiproliferative drug coating, and the principles behind the design. Although a number of smaller studies have highlighted the potential of dedicated bifurcation stents (Table 3), clinical benefit has yet to be demonstrated in large scale randomized clinical trials.

Dedicated bifurcation stents can be largely grouped under three headings: those designed to treat the side branch first (eg, Tryton [Tryton Medical, Durham, NC, USA] or Sideguard [Cappella Medical Devices, Galway, Ireland]); those that facilitate provisional side branch stenting while maintaining direct access to the side branch after main vessel stenting (eg, Xience Side Branch Access [SBA] [Abbott Vascular]); and conical stents (eg, Axxess stent [Biosensors International, Singapore]).

The Tryton Side Branch stent system is a cobalt chromium BMS (strut thickness $83 \mu \mathrm{m}$ ), which is deployed in the side branch artery first using a standard single wire balloon expandable delivery system. A conventional DES is then deployed in the main vessel through the scaffolding extending proximally into the main branch. The Tryton stent provides minimal strut coverage in main vessel, full strut coverage at the side branch ostium, and the ability to adapt to a wide spectrum of bifurcation angles and sizes. The bare 


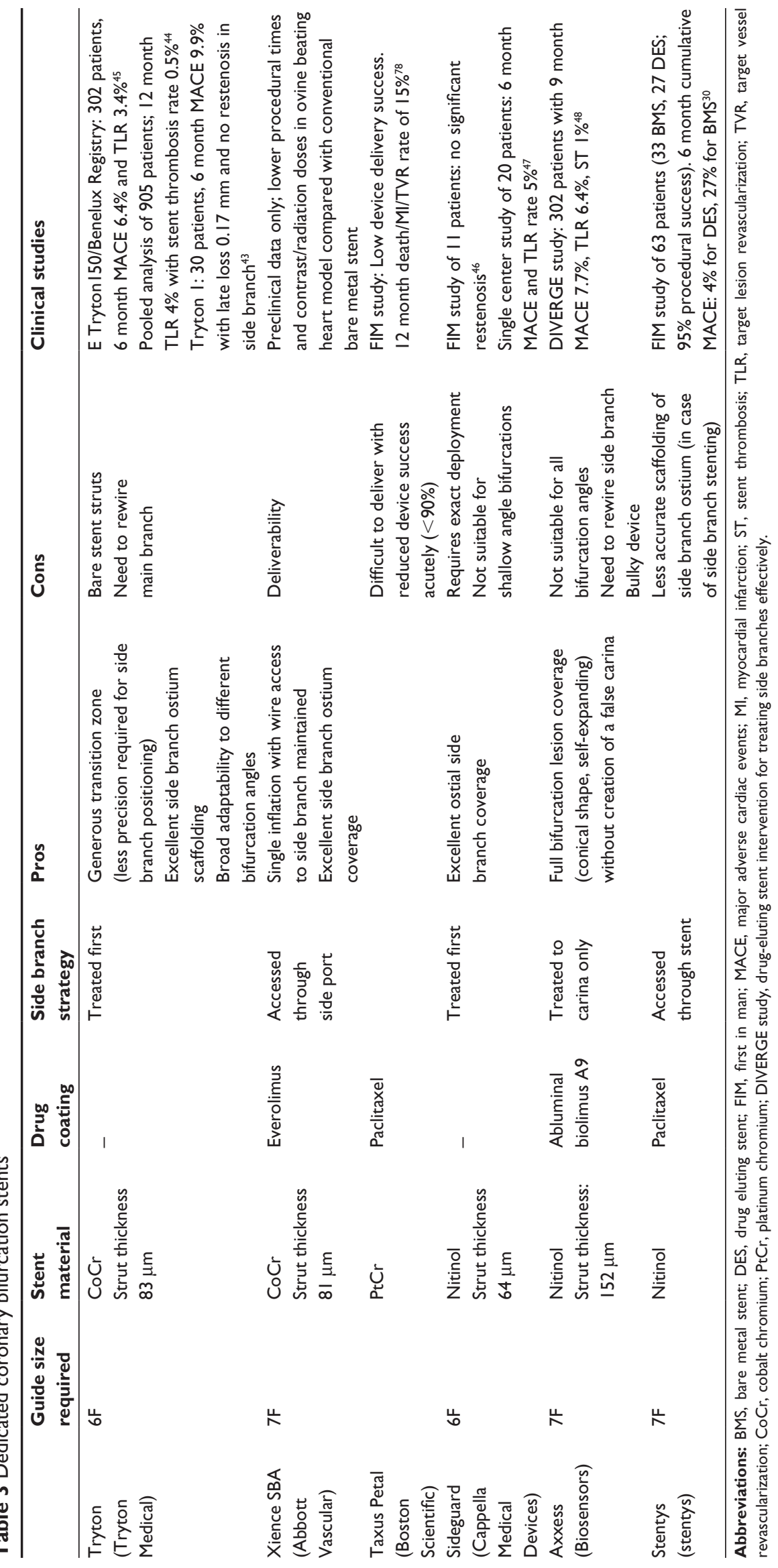


struts in the side branch do not seem to predispose to side branch in-stent restenosis. ${ }^{43-45}$ The Tryton IDE study, a randomized comparison of a dedicated two stent strategy using the Tryton stent with a conventional provisional bifurcation stenting strategy in over 700 patients, has recently completed enrolment.

The Sideguard stent is a novel nitinol self-expanding BMS (64 $\mu \mathrm{m}$ strut thickness) that flares proximally at the ostium of the side branch into a trumpet shape to facilitate full ostial side branch coverage. It is usually used in combination with a conventional DES in the main branch. This stent appears attractive for use in lesions with bifurcation angles greater than 70 degrees, but should be avoided in shallow angle bifurcations (less than 40 degrees). Its feasibility as a bifurcation stent was demonstrated in a first-in-man study of eleven patients ${ }^{46}$ (no significant restenosis was seen at 6 month follow-up) and in a small single center UK study ${ }^{47}$ (successful deployment in 20 patients; major adverse cardiac events in $5 \%$ of patients at 6 months). Longer term efficacy data are awaited.

Multiple stents with preformed side ports to facilitate access to the side branch exist. The Xience SBA stent is an everolimus eluting stent that provides wire access into the side branch regardless of the planned treatment strategy. A single inflation deploys the stent in the main branch and opens a portal into the side branch.

The Axxess stent is a self-expanding, drug eluting (Biolimus A9), conical shaped nitinol stent, which is deployed by withdrawal of a covering sheath (Figure 4). It should be deployed at the level of the carina, thus providing scaffolding to the bifurcation and ostia of both side branches while leaving the true carina free of metal and affording easy access

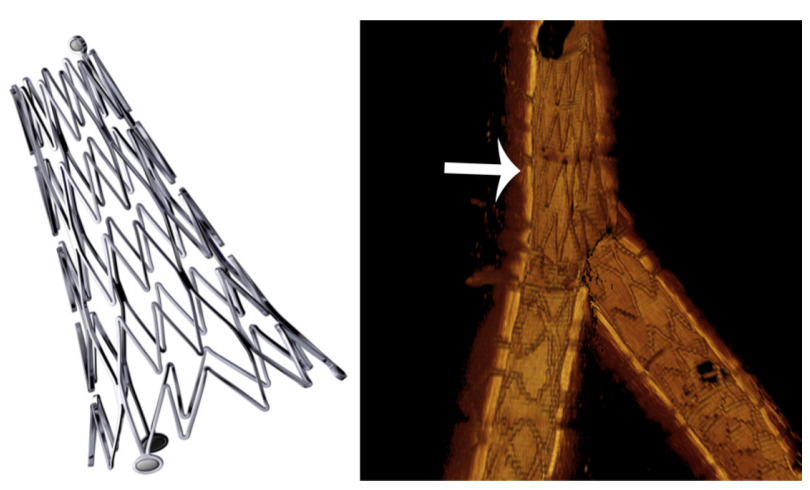

Figure 4 The Axxess bifurcation stent (Biosensors International, Singapore). Notes: This is a conical, self-expanding nitinol stent eluting the drug Biolimus A9 (left panel). The figure is a three dimensional reconstruction of optical coherence tomography pullback images following implantation of an Axxess stent in a bifurcation lesion. The arrow depicts the Axxess stent. Additional conventional drug eluting stents have also been implanted in the downstream limbs of the bifurcation. to both distal branches, which can be treated with conventional stents as required, although this stent can stand alone. It performs best in shallow angle bifurcation lesions, and is not recommended for bifurcation angles of $>70$ degrees. As with any self-expanding device, adequate lesion preparation is critical prior to stent deployment. The device was tested in the DIVERGE (Drug eluting Stent Intervention for Treating Side Branches Effectively) study where 302 patients had bifurcation lesions treated with the Axxess stent; $22 \%$ patients required additional stenting of one branch and $65 \%$ required stenting of both branches, while rates of major adverse events, target lesion revascularization, and stent thrombosis were $7.7 \%, 6.4 \%$, and $1 \%$, respectively, at 9 month follow-up. ${ }^{48}$

\section{Drug delivery systems}

The realization that stent scaffolds can be used as vehicles to target local drug delivery directly to the vessel wall revolutionized PCI. Following the emergence of DES in 2002, the antiproliferative agents sirolimus (and its metabolites) and paclitaxel have been the predominant drugs eluted by DES. Polymer coatings were developed to deliver these antiproliferative drugs in a controlled and uniform manner. The polymer can either be applied over the drug or the drug can be dispersed within the coat, with the pharmacokinetics of drug release affected by altering physical or chemical properties of the polymer coating.

In early generation DES, the polymers used to deliver antiproliferative drugs (on Cypher [Cordis, Bridgewater, NJ, USA] and Taxus [Boston Scientific] stents) were not designed for vascular compatibility and were linked to inflammation and stent thrombosis. ${ }^{4-52}$ This led to efforts to develop biologically inert (but nonerodable) polymers. Several trials have demonstrated a very low incidence of stent thrombosis with these newer agents when compared to the first generation DES. ${ }^{52-54}$

More recently, fully biodegradable polymer coatings have been developed. These afford drug delivery through loading and elution of a lipophilic drug from a biocompatible polymer (to prevent restenosis early poststent insertion), which is slowly degraded into inert organic monomers, thereby removing the risk associated with persistent polymer residue in the vessel wall. Numerous biodegradable polymer stents have been evaluated in clinical trials and appear non-inferior to permanent polymer stents. These include the Nobori biolimus A9 eluting stent (Terumo Corporation, Tokyo, Japan), ${ }^{55}$ the Biomatrix Flex biolimus A9 eluting stent (Biosensors International), ${ }^{56}$ the Synergy everolimus eluting stent (Boston Scientific), ${ }^{57}$ and the Yukon Choice PC 
rapamycin eluting stent (Translumina Therapeutics, Hechingen, Germany) ${ }^{58}$ A meta-analysis of pooled individual data from the ISAR-TEST (intracoronary stenting and angiographic restenosis - test equivalence between two drug-eluting stents) ${ }^{58}$ and LEADERS (long-term clinical outcomes of biodegradable polymer biolimus-eluting stents versus durable polymer sirolimus-eluting stents in patients with coronary artery disease [LEADERS]: 4 year follow-up of a randomised non-inferiority trial $)^{56}$ trials revealed the risk of target lesion revascularization and stent thrombosis to be lower at 4 years in patients treated with bioresorbable polymer when compared to durable polymer drug eluting stents (hazard ratios of 0.82 [95\% CI $0.68-0.98$ ] and 0.56 [95\% CI 0.35-0.90], respectively). ${ }^{59}$

Concerns regarding polymer mediated stent thrombosis have also led to development of novel polymer-free DES. Several approaches have been examined, including microtextured stainless steel reservoirs in cobalt chromium struts and carbon coated slotted struts. The Yukon stent (Translumina, Hechingen, Germany) has a roughened stent surface to which a drug solution can be applied in the catheterization laboratory. In a clinical study of 400 patients undergoing PCI, the Yukon stent coated with a $2 \%$ rapamycin solution was shown not to be inferior, in terms of late loss at 9 months, when compared to a contemporary DES. ${ }^{60}$

The BioFreedom stent (Biosensors International, Singapore) is a stainless steel scaffold modified by microabrasion to create a highly textured abluminal surface (Figure 5). This allows drug (Biolimus A9) adhesion to the stent's abluminal surface without the use of a polymer. Preliminary data from a first-in-man study with follow-up to 3 years are encouraging

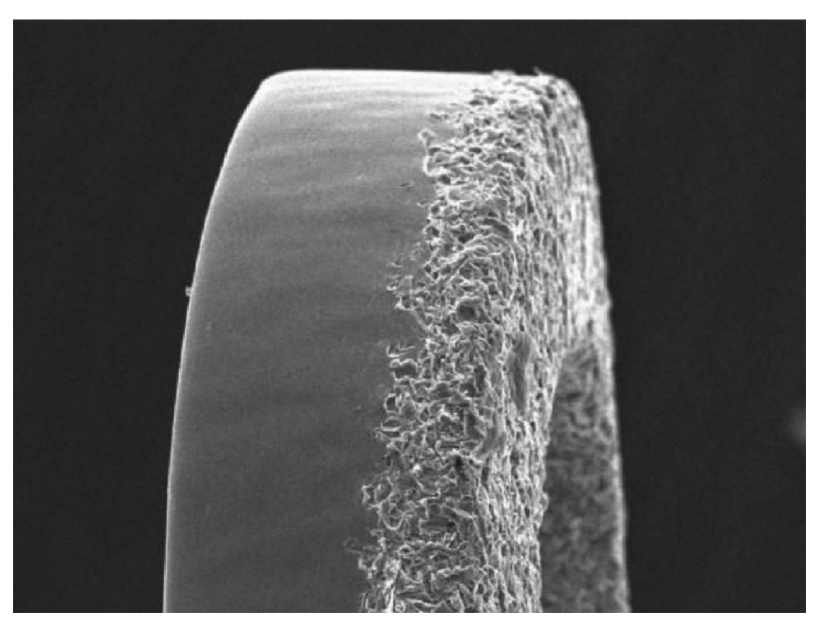

Figure 5 The roughened surface of the BioFreedom ${ }^{T M}$ stent (Biosensors International, Singapore) acts as a reservoir for an antiproliferative agent without the need for a polymer coating. with comparable rates of in-stent late loss at 12 months when compared to a paclitaxel eluting stent (Taxus Liberte). ${ }^{61}$

\section{Novel stent coatings}

With an abluminal coating of the CD34 antibody on a bare metal stainless steel scaffold, the Genous stent (OrbusNeich, Fort Lauderdale, FL, USA) was developed to sequester circulating endothelial cell progenitors from the blood stream in an attempt to accelerate endothelialization and reduce stent thrombosis. While data from the e-Healing Registry of over 5000 patients undergoing PCI are encouraging with rates of target lesion revascularization and stent thrombosis of $5.7 \%$ and $1.1 \%$, respectively, at 12 month follow-up, ${ }^{62}$ a head to head comparison with contemporary DES reported higher rates of target vessel failure with the Genous stent at 12 months, ${ }^{63}$ although this difference was no longer statistically significant at 2 years. ${ }^{64}$ A novel stent (Combo Dual Therapy stent; OrbusNeich, Fort Lauderdale, FL, USA) combining CD34 antibody technology with the antiproliferative agent, sirolimus, and a biodegradable polymer coating has recently been approved for use in Europe.

The Titan-2 BioActive stent ${ }^{\mathrm{TM}}$ (Hexacath, Paris, France) is constructed from stainless steel coated in titanium nitric oxide. Nitric oxide is an endogenous signaling molecule that induces vasodilatation and inhibits both platelet aggregation and smooth muscle cell proliferation. A deficiency in the vasodilator, nitric oxide, has been associated with instent restenosis and stent thrombosis. ${ }^{65}$ A number of initial small studies have demonstrated that the Titan-2 stent was superior to conventional BMS, ${ }^{66}$ and equivalent to paclitaxel (TITAX-AMI [titanium-nitric-oxide coated stents versus paclitaxel-eluting stents in acute myocardial infarction] $)^{67}$ and everolimus eluting stents, ${ }^{68}$ at reducing in-stent late loss. At 5 years follow-up in the TITAX-AMI titanium-nitric-oxide coated stents versus paclitaxel-eluting stents in acute myocardial infarction study, the Titan-2 stent was associated with similar rates of target lesion revascularization and a lower incidence of death or recurrent myocardial infarction when compared to paclitaxel DES. ${ }^{69}$

In addition to nitric oxide donors, stents coated with genetic information targeting nitric oxide metabolism have received attention. As an example, stent struts coated with lipopolyplexes expressing nonviral plasmid DNA encoding endothelial nitric oxide synthase, an enzyme that catalyzes the production of nitric oxide from L-arginine, have been shown to inhibit neointimal hyperplasia. ${ }^{70}$ Similarly, an in vivo study using stents coated with lipopolyplexes containing endothelial nitric oxide synthase DNA demonstrated accelerated 
endothelialization, albeit without suppressing neointimal formation. ${ }^{71}$ Whether this strategy will be successful in the clinical arena remains to be determined.

\section{Drug eluting balloons}

Balloon angioplasty using drug eluting balloons has emerged as an alternative to stent insertion for the treatment of in-stent restenosis and in small diameter coronary vessels. Drug eluting balloons allow for local application of an antiproliferative agent at the time of barotrauma, avoiding the need for a persistent metal scaffold - a potential nidus for inflammation and restenosis. Paclitaxel is the drug most commonly applied to drug eluting balloons owing to its rapid uptake, as promoted by its highly lipophilic properties and tight binding to various cell constituents. The major differences between currently available drug eluting balloons relates largely to the loading dose, the way in which the balloon is coated (360 degrees or partial), and the excipient (an ingredient added to the drug to facilitate its uptake). A brief summary of contemporary drug eluting balloons is presented in Table 4 .

A recent meta-analysis of five studies suggested that balloon angioplasty with a drug eluting balloon was superior to conventional balloon angioplasty alone, and at least equiva- lent to paclitaxel eluting DES use in patients with in-stent restenosis. ${ }^{72}$ In this study, drug eluting balloons reduced the risk for major adverse cardiac events (Relative Risk 0.46, $0.31-0.70 ; P<0.001)$, mainly driven by a reduction in target lesion revascularization ( $\mathrm{RR} 0.34,0.16-0.73 ; P=0.006)$ and also by a lower mortality risk (RR $0.48,0.24-0.95 ; P=0.034$ ) when compared to conventional balloon angioplasty alone or DES use. In addition, late luminal loss $(-0.38 \mathrm{~mm},-0.6$ to $-0.15, P=0.001)$ and rates of in-segment binary restenosis (28\%, 14\%-58\%, $P<0.001)$ were lower with drug eluting balloon use..$^{72}$

Drug eluting balloons have also demonstrated potential for the treatment of small diameter vessels where stent insertion, even if drug eluting, is associated with higher rates of restenosis. The recently published BELLO (Balloon Elution and Late Loss Optimization) study demonstrated that use of the IN.PACT FALCON drug eluting balloon (Medtronic, Santa Rosa, CA, USA) was associated with significantly less late loss when compared to paclitaxel eluting stent use in small caliber arteries (defined as $<2.8 \mathrm{~mm}$ diameter, but $89 \%$ of arteries were $<2.5 \mathrm{~mm}$ ). ${ }^{73}$ There was no difference in secondary clinical endpoints between the two strategies at 6 months. These findings are in contrast to the smaller,

Table 4 Contemporary drug eluting balloons

\begin{tabular}{|c|c|c|c|}
\hline DEB & Drug & Design & Clinical scenarios \\
\hline IN.PACT FALCON & Paclitaxel & Coated balloon & Native small vessels: \\
\hline (Medtronic-Invatec, & & Excipient, urea & BELLO: Randomized comparison with TAXUS DES in small \\
\hline Switzerland) & & Dose density $3 \mu \mathrm{g} / \mathrm{mm}^{2}$ & vessels. Clinical outcomes similar at 6 months ${ }^{73}$ \\
\hline Sequent Please & Paclitaxel & Coated balloon & Native small vessels: \\
\hline (B Braun Melsungen & & Excipient, iopromide (contrast media) & PEPCAD I SVD (native small vessels): I 2 month MACE \\
\hline \multirow[t]{11}{*}{ AG, Germany) } & & Dose density $3 \mu \mathrm{g} / \mathrm{mm}^{2}$ & rate of $15 \%$ and mean late loss of $0.28 \mathrm{~mm}^{75}$ \\
\hline & & & Native vessels (any size): \\
\hline & & & PEPCAD III: DEB + BMS versus Cypher DES failed to meet \\
\hline & & & noninferiority criteria ${ }^{76}$ \\
\hline & & & Chronically occluded vessels: \\
\hline & & & PEPCAD-CTO: BMS + DEB inferior to Taxus ${ }^{77}$ \\
\hline & & & In-stent Restenosis: \\
\hline & & & PEPCAD II (versus Taxus) - MACE RR $0.42(0.17-I .03)^{79}$ \\
\hline & & & ISAR-DESIRE (versus Taxus) - MACE RR $0.72(0.5 \mathrm{I}-\mathrm{I} .02)^{80}$ \\
\hline & & & PEPCAD-DES (versus POBA) - MACE RR $0.33(0.18-0.61)^{81}$ \\
\hline & & & Habara et al (versus POBA) - MACE RR 0.I $(0.01-0.72)^{82}$ \\
\hline Dior I/II (Eurocor, & Paclitaxel & Nanoporous balloon & Native small vessels: \\
\hline \multirow[t]{2}{*}{ Germany) } & & Excipient, Dimethylsulfate/shellac & PICCOLETO (Dior I): stopped prematurely as inferior \\
\hline & & Dose density $3 \mu \mathrm{g} / \mathrm{mm}^{2}$ & to Taxus stent ${ }^{74}$ \\
\hline Paccocath (Bayer AG, & Paclitaxel & Coated balloon & In-stent Restenosis \\
\hline \multirow[t]{2}{*}{ Leverkusen, Germany) } & & Excipient, iopromide (contrast media) & PACCOCATH: lower MACE and TLR compared with \\
\hline & & Dose density $3 \mu \mathrm{g} / \mathrm{mm}^{2}$ & $\mathrm{POBA}^{83}$ \\
\hline Elutax (Aachen & Paclitaxel & Coated balloon & Native vessels and Restenosis: \\
\hline Resonance $\mathrm{GmbH}$, & & Excipient, none & Higher restenosis rate (12.5\%) versus Sequent Please (3.4\%) \\
\hline Germany) & & Dose density $2 \mu \mathrm{g} / \mathrm{mm}^{2}$ & at 6 months $^{84}$ \\
\hline
\end{tabular}

Abbreviations: BMS, bare metal stent, DEB; drug eluting balloon; DES, drug eluting stent; MACE, major adverse cardiac events; POBA, balloon angioplasty alone; RR, relative risk; TLR, target lesion revascularization; BELLO, Balloon elution and late optimization" study; PEPCAD-CTO, paclitaxel-eluting PTCA-balloon catheter to treat chronic total occlusions; PICCOLETO, paclitaxel-coated balloon versus drug-eluting stent during $\mathrm{PCl}$ of small coronary vessels, a prospective randomised clinical trial. 
single center PICCOLETO (paclitaxel-coated balloon versus drug-eluting stent during PCI of small coronary vessels, a prospective randomised clinical trial) study which was stopped prematurely as the Dior balloon (Eurocor, Bonn, Germany) was clearly inferior to a paclitaxel DES in small vessels. ${ }^{73}$ In the PEPCAD I SVD (treatment of small coronary arteries with a paclitaxel-coated balloon catheter) trial, 118 patients with stenosis in small coronary vessels were treated with the SeQuent Please balloon catheter (B Braun, Melsungen, Germany). ${ }^{75}$ Thirty percent of patients required additional stent deployment, and mean late loss was $0.28 \pm$ $0.53 \mathrm{~mm}$, with an adverse event rate of $15 \%$ at 12 months, driven largely by recurrent target lesion revascularization. ${ }^{75}$

It has been suggested that combining BMS implantation with drug eluting balloon use in native coronary arteries may offer an alternative strategy to DES implantation. However, clinical data do not currently support this strategy. ${ }^{76,77}$

Drug eluting balloons afford a number of theoretical advantages over DES including a lower potential risk of stent thrombosis and a requirement for a shorter duration of dual antiplatelet therapy. One strategy for the treatment of multivessel disease might be to reserve DES use for major proximal epicardial vessels, performing balloon angioplasty alone, perhaps using a cutting or scoring balloon, followed by a drug eluting balloon to distal lesions or diseased side branches. This strategy, however, remains to be tested in clinical trials.

\section{Summary}

There is no doubt that the development of the coronary stent has progressed rapidly over recent years. Despite these advances, the optimal coronary scaffold remains elusive. Desirable features include ease of delivery in challenging vessels without compromising radial and longitudinal strength, adequate radio-opacity to facilitate stent positioning and visualization, and appropriate targeted delivery of an antiproliferative agent that inhibits smooth muscle proliferation without delaying endothelialization, stimulating inflammation, or promoting thrombosis. Achieving these goals is challenging but central to the future progression of coronary artery stent technology.

\section{Disclosure}

Dr Cruden has received sponsorship to attend scientific meetings and consultancy fees from St Jude Medical, an unrestricted Fellowship Award and sponsorship to attend scientific meetings from Boston Scientific, and research funding from Medtronic.

\section{References}

1. Roubin GS, Canon AD, Agrawal SK, et al. Intracoronary stenting for acute and threatened closure complicating percutaneous transluminal coronary angioplasty. Circulation. 1992;85:916-927.

2. Epstein AJ, Polsky D, Yang F, Lin Yang L, Groeneveld PW. Coronary revascularization trends in the United States: 2001-2008. JAMA. 2011;305: 1769-1776.

3. Garg S, Serruys PW. Coronary stents. J Am Coll Cardiol. 2010;56: $\mathrm{S} 1-\mathrm{S} 42$.

4. Luscher TF, Steffel J, Eberli F, et al. Drug-eluting stent and coronary thrombosis: biological mechanisms and clinical implications. Circulation. 2007;115:1051-1058.

5. Fischman DL, Leon MB, Baim DS, et al. A randomized comparison of coronary-stent placement and balloon angioplasty in the treatment of coronary artery disease. Stent Restenosis Study Investigators. N Engl J Med. 1994;331:496-501.

6. Serruys PW, de Jaegere P, Kiemeneij F, et al. A comparison of balloonexpandable-stent implantation with balloon angioplasty in patients with coronary artery disease. Benestent Study Group. N Engl J Med. 1994;331: 489-495.

7. Jukema JW, Verschuren JW, Tan A, Quax PH. Restenosis after PCI. Part 1: pathophysiology and risk factors. Nat Rev Cardiol. 2011;9:53-62.

8. Gyöngyösi M, Yang P, Khorsand A, Glogar D. Longitudinal straightening effect of stents is an additional predictor for major adverse cardiac events. Austrian Wiktor Stent Study Group and European Paragon Stent Investigators. J Am Coll Cardiol. 2000;35:1580-1589.

9. Silber S, Windecker S, Vranckx P, Serruys PW; RESOLUTE All Comers investigators. Unrestricted randomised use of two new generation drugeluting coronary stents: 2-year patient-related versus stent-related outcomes from the RESOLUTE All Comers trial. Lancet. 2011;377:1241-1247.

10. Doyle BJ, Rihal CS, Gastineau DA, Holmes DR Jr. Bleeding, blood transfusion, and increased mortality after percutaneous coronary intervention: implications for contemporary practice. J Am Coll Cardiol. 2009;53:2019-2027.

11. Cruden NL, Harding SA, Flapan AD, et al; Scottish Coronory Revascularisation Register Steering Committee. Previous coronary stent implantation and cardiac events in patients undergoing noncardiac surgery. Circ Cardiovasc Interv. 2010;3:236-242.

12. Dewilde WJ, Oirbans T, Verheugt FW, et al; WOEST study investigators. Use of clopidogrel with or without aspirin in patients taking oral anticoagulant therapy and undergoing percutaneous coronary intervention: an open-label, randomised, controlled trial. Lancet. 2013;381: 1107-1115.

13. Moreno R, Jimenez-Valero S, Sanchez-Recalde A, et al. Periprocedural (30day) risk of myocardial infarction after drug-eluting coronary stent implantation: a meta-analysis comparing cobalt-chromium and stainless steel drug-eluting coronary stents. EuroIntervention. 2011;6: 1003-1010.

14. Kastrati A, Mehilli J, Dirschinger J, et al. Intracoronary stenting and angiographic results: strut thickness effect on restenosis outcome (ISAR-STEREO) trial. Circulation. 2001;103:2816-2821.

15. Sketch MH, Ball M, Rutherford B, Pompa JJ, Russell C, Kereiakes DJ; Driver investigators. Evaluation of the Medtronic (Driver) cobaltchromium alloy coronary stent system. Am J Cardiol. 2005;95:8-12.

16. Reifart N, Morice MC, Silber S, et al; NUGGET study. The NUGGET study: NIR ultra gold-gilded equivalency trial. Catheter Cardiovasc Interv. 2004;62:18-25.

17. Hanratty CG, Walsh SJ. Longitudinal compression: a "new" complication with modern coronary stent platforms - time to think beyond deliverability? EuroIntervention. 2011;7:872-877.

18. Hofma SH, van der Giesen WJ, van Dalen BM, et al. Indication of longterm endothelial dysfunction after sirolimus-eluting stent implantation. Eur Heart J. 2006;27:166-170.

19. Waksman R, Erbel R, Di Mario C, et al; PROGRESS-AMS (Clinical Performance and Angiographic Results of Coronary Stenting with Absorbable Metal Stents) Investigators. Early- and long-term intravascular ultrasound and angiographic findings after bioabsorbable magnesium stent implantation in human coronary arteries. JACC Cardiovasc Interv. 2009;2:312-320. 
20. Ormiston JA, Serruys PW. Bioabsorbable coronary stents. Circ Cardiovasc Interv. 2009;2:255-260.

21. Nishio S, Kosuga K, Igaki K, et al. Long-Term ( $>10$ Years) clinical outcomes of first-in-human biodegradable poly-1-lactic acid coronary stents: Igaki-Tamai stents. Circulation. 2012;125:2343-2353.

22. Ormiston JA, Serruys PW, Regar E, et al. A bioabsorbable everolimuseluting coronary stent system for patients with single de-novo coronary artery lesions (ABSORB): a prospective open-label trial. Lancet 2008;371:899-907.

23. Serruys PW, Ormiston JA, Onuma Y, et al. A bioabsorbable everolimuseluting coronary stent system (ABSORB): 2 year outcomes and results from multiple imaging methods. Lancet. 2009;373:897-910.

24. Onuma Y. Three year results of clinical follow-up after a bioresorbable everolimus-eluting scaffold in patients with de novo coronary artery disease: the ABSORB trial. EuroIntervention. 2010;6:447-453.

25. Yamawaki T, Shimokawa H, Kozai T, et al. Intramural delivery of a specific tyrosine kinase inhibitor with biodegradable stent suppresses the restenotic changes of the coronary artery in pigs in vivo. $J \mathrm{Am}$ Coll Cardiol. 1998;32:780-786.

26. ABSORB II randomized controlled trial: a clinical evaluation to compare the safety, efficacy, and performance of the Absorb everolimus-eluting bioresorbable vascular scaffold system against the XIENCE everolimus-eluting coronary stent system in the treatment of subjects with ischemic heart disease caused by de novo native coronary artery lesions: rationale and study design. Diletti R, Serruys PW, Farooq V, et al. Am Heart J. 2012;164:654-63.

27. Haude M, Erbel R, Erne P, et al. Safety and performance of the drugeluting absorbable metal scaffold (DREAMS) in patients with de-novo coronary lesions: 12 month results of the prospective, multicentre, first-in-man BIOSOLVE-I trial. Lancet. 2013;381:836-844.

28. Jabara R, Pendyala L, Geve S, Chen J, Chronos N, Robinson K. Novel fully bioabsorbable salicylate-based sirolimus eluting stent. EuroIntervention. 2009;5 Suppl F:F58-F64.

29. Strauss BH, Serruys PW, Bertrand ME, et al. Quantitative angiographic follow-up of the coronary Wallstent in native vessels and bypass grafts (European experience - Mar 1986 to Mar 1990). Am J Cardiol. 1992;69:475-481.

30. Verheye S, Ramcharitar S, Grube E, et al. Six-month clinical and angiographic results of the STENTYS ${ }^{\circledR}$ self-apposing stent in bifurcation lesions. EuroIntervention. 2011;7:580-587.

31. van Geuns R, Tamburino C, Fajadet J, et al. Self-expanding versus balloonexpandable stents in acute myocardial infarction: results from the APPOSITION II Study. Self-expanding stents in ST-segment elevation myocardial infarction. JACC Cardiovasc Interv. 2012;5:1209-1219.

32. Abizaid AC, de Ribamar Costa J, Whitbourn RJ, Chang JC. The CardioMind coronary stent delivery system: stent delivery on a $0.014^{\prime \prime}$ guidewire platform. EuroIntervention. 2007;3:154-157.

33. Chamie D, Costa R, Abizaid A, et al. Serial angiography and intravascular ultrasound: results of the SISC Registry (Stents In Small Coronaries). JACC Cardiovasc Interv. 2010;3:191-202.

34. Kume T, Waseda K, Koo BK, et al. Intravascular ultrasound analysis of small vessel lesions treated with the sparrow coronary stent system: results of the CARE II trial. Catheter Cardiovasc Interv. [Epub February 14, 2013.]

35. Stone GW, Dizon JM, Merkely B, et al. Prospective, randomized, multicenter evaluation of a polyethylene terephthalate micronet meshcovered stent (MGuard) in ST-segment elevation myocardial infarction the MASTER Trial. J Am Coll Cardiol. 2012;60:1975-1984.

36. Behan MW, Holm NR, Curzen NP, et al. Simple or complex stenting for bifurcation coronary lesions. A patient-level pooled-analysis of the Nordic Bifurcation Study and the British Bifurcation Coronary Study. Circ Cardiovasc Interv. 2011;4:57-64.

37. Pan M, de Lezo JS, Medina A, et al. Rapamycin-eluting stents for the treatment of bifurcated coronary lesions: a randomized comparison of a simple versus complex strategy. Am Heart J. 2004;148:857-864.

38. Jensen JS, Galløe A, Lassen JF, et al; Nordic-Baltic PCI Study Group Safety in simple versus complex stenting of coronary artery bifurcation lesions. The nordic bifurcation study 14-month follow-up results. EuroIntervention. 2008;4:229-233.
39. Hildick-Smith D, de Belder AJ, Cooter N, et al. Randomized trial of simple versus complex drug-eluting stenting for bifurcation lesions: the British Bifurcation Coronary Study: old, new, and evolving strategies. Circulation. 2010;121:1235-1243.

40. Colombo A, Bramucci E, Sacca S, et al. Randomized study of the crush technique versus provisional side-branch stenting in true coronary bifurcations: the CACTUS (Coronary Bifurcations: Application of the Crushing Technique Using Sirolimus-Eluting Stents) study. Circulation. 2009;119:71-78.

41. Zhang F, Dong L, Ge J. Simple versus complex stenting strategy for coronary artery bifurcation lesions in the drug-eluting stent era: a metaanalysis of randomized trials. Heart. 2009;95:1676-1681.

42. Katritsis DG, Siontis GCM, Ioannidis JPA. Double versus single stenting for coronary bifurcation lesions: a meta-analysis. Circ Cardiovasc Interv. 2009;2:409-415.

43. Onuma Y, Müller R, Ramcharitar S, et al. Tryton I, First-In-Man (FIM) study: six month clinical and angiographic outcome, analysis with new quantitative coronary angiography dedicated for bifurcation lesions. EuroIntervention. 2008;3:546-552.

44. Grundeken MJ, Asgedom S, Damman P, et al. Six-month and one-year clinical outcomes after placement of a dedicated coronary bifurcation stent: a patient-level pooled analysis of eight registry studies. EuroIntervention. [Epub January 30, 2013.]

45. Agostoni P, Foley D, Lesiak M, et al. A prospective multicentre registry, evaluating real-world usage of the Tryton side branch stent: results of the E-Tryton 150/Benelux registry. EuroIntervention. 2012;7:1293-1300.

46. Doi H, Maehara A, Mintz GS, Dani L, Leon MB, Grube E. Serial intravascular ultrasound analysis of bifurcation lesions treated using the novel self-expanding sideguard side branch stent. Am J Cardiol. 2009;104:1216-1221.

47. Mamas MA, Farooq V, Latib A, et al. Use of the Sideguard (Cappella) stent in bifurcation lesions: a real-world experience. EuroIntervention. 2012;7:1170-1180.

48. Verheye S, Agostoni P, Dubois CL, et al. 9-month clinical, angiographic, and intravascular ultrasound results of a prospective evaluation of the Axxess self-expanding biolimus A9-eluting stent in coronary bifurcation lesions: the DIVERGE (Drug-Eluting Stent Intervention for Treating Side Branches Effectively) study. J Am Coll Cardiol. 2009;53: 1031-1039.

49. Cook S, Ladich E, Nakazawa G, et al. Correlation of intravascular ultrasound findings with histopathological analysis of thrombus aspirates in patients with very late drug-eluting stent thrombosis. Circulation. 2009;120:391-399.

50. Nakazawa G, Ladich E, Finn AV, Virmani R. Pathophysiology of vascular healing and stent mediated arterial injury. EuroIntervention. 2008;4(Suppl C):C7-C10.

51. Nebeker JR, Virmani R, Bennett CL, et al. Hypersensitivity cases associated with drug-eluting coronary stents: a review of available cases from the Research on Adverse Drug Events and Reports (RADAR) project. J Am Coll Cardiol. 2006;47:175-181.

52. Stone GW, Rizvi A, Newman W, et al; SPIRIT IV Investigators. Everolimus-eluting versus paclitaxel-eluting stents in coronary artery disease. $N$ Engl J Med. 2010;362(18):1663-1674.

53. Kedhi E, Joesoef KS, McFadden E, et al. Second-generation everolimuseluting and paclitaxel-eluting stents in real-life practice (COMPARE) a randomised trial. Lancet. 2010;375:201-209.

54. Serruys PW, Silber S, Garg S, et al. Comparison of zotarolimus-eluting and everolimus-eluting coronary stents. $N$ Engl J Med. 2010;363: 136-146.

55. Chevalier B, Silber S, Park SJ, et al; NOBORI 1 Clinical Investigators. Randomized comparison of the Nobori Biolimus A9-eluting coronary stent with the Taxus Liberté paclitaxel-eluting coronary stent in patients with stenosis in native coronary arteries: the NOBORI 1 trial-Phase 2. Circ Cardiovasc Interv. 2009;2:188-195.

56. Stefanini GG, Kalesan B, Serruys PW, et al. Long-term clinical outcomes of biodegradable polymer biolimus-eluting stents versus durable polymer sirolimus-eluting stents in patients with coronary artery disease (LEADERS): 4 year follow-up of a randomised non-inferiority trial Lancet. 2011;378:1940-1948. 
57. Meredith IT, Verheye S, Dubois CL, et al. Primary endpoint results of the EVOLVE trial: a randomized evaluation of a novel bioabsorbable polymer-coated, everolimus-eluting coronary stent. J Am Coll Cardiol. 2012;59:1362-1370.

58. Byrne RA, Kastrati A, Kufner S, et al; Intracoronary Stenting and Angiographic Results: Test Efficacy of 3 Limus-Eluting Stents (ISARTEST-4) Investigators. Randomized, non-inferiority trial of three limus agent-eluting stents with different polymer coatings: the Intracoronary Stenting and Angiographic Results: Test Efficacy of 3 Limus-Eluting Stents (ISAR-TEST-4) Trial. Eur Heart J. 2009;30:2441-2449.

59. Stefanini GG, Byrne RA, Serruys PW, et al. Biodegradable polymer drug-eluting stents reduce the risk of stent thrombosis at 4 years in patients undergoing percutaneous coronary intervention: a pooled analysis of individual patient data from the ISAR-TEST 3, ISAR-TEST 4, and LEADERS randomized trials. Eur Heart J. 2012;33: 1214-1222.

60. Mehilli J, Kastrati A, Wessely R, et al; Intracoronary Stenting and Angiographic Restenosis-Test Equivalence Between 2 Drug-eluting Stents (ISAR-TEST) Trial Investigators. Randomized trial of a nonpolymer-based Rapamycin-eluting stent versus a polymer-based Paclitaxel-eluting stent for the reduction of late lumen loss. Circulation. 2006;113:273-279.

61. Grube E, Mueller R, Schuler G, Hauptmann K, Schofer J. Comparison of Polymer-Free BioFreedom ${ }^{\mathrm{TM}}$ Stents with Durable Polymer Taxus LibertéTM Stents: 3-Year Results from the BioFreedom First-In-Man Trial. J Am Coll Cardiol. 2012;60(17_S).

62. Silber S, Damman P, Klomp M. Clinical results after coronary stenting with the Genous Bio-engineered R stent: 12-month outcomes of the e-HEALING (Healthy Endothelial Accelerated Lining Inhibits Neointimal Growth) worldwide registry. EuroIntervention. 2011;6: 819-825.

63. Beijk MA, Klomp M, Verouden NJ, et al. Genous endothelial progenitor capturing stent vs the Taxis Liberte stent in patients with de novo coronary lesions with a high risk of coronary restenosis: a randomized, single-centre, pilot study. Eur Heart J. 2010;31:1055-1064.

64. Beijk MA, Klomp M, van Geloven N, et al. Two-year follow-up of the Genous $^{\mathrm{TM}}$ endothelial progenitor cell capturing stent versus the Taxus Liberté stent in patients with de novo coronary artery lesions with a high-risk of restenosis: a randomized, single-center, pilot study. Catheter Cardiovasc Interv. 2011;78:189-195.

65. Gorchakova O, Koch W, Beckerath N, Mehill J, Schomig A, Kastrati A. Association of a genetic variant of endothelial nitric oxide synthase with the 1 year clinical outcome after coronary stent placement. Eur Heart $J$. 2003;24:820-827.

66. Moschovitis A, Simon R, Seidenstücker A, et al. Randomised comparison of titanium-nitride-oxide coated stents with bare metal stents: five-year follow-up of the TiNOX trial. EuroIntervention. 2010;6:63-68.

67. Karjalainen PP, Ylitalo A, Niemelä M, et al. Two-year follow-up after percutaneous coronary intervention with titanium-nitride-oxide-coated stents versus paclitaxel-eluting stents in acute myocardial infarction. Ann Med. 2009;41:599-607.

68. Karjalainen PP, Ylitalo A, Niemelä M, et al. Titanium-nitride-oxide coated stents versus paclitaxel eluting stents in acute myocardial infarction: a 12-month follow-up report from the TITAX AMI trial. EuroIntervention. 2008;4:234-241.

69. Tuomainen PO, Ylitalo A, Niemelä M, et al. Five-year clinical outcome of titanium-nitride-oxide-coated bioactive stents versus paclitaxel-eluting stents in patients with acute myocardial infarction: long-term follow-up from the TITAX AMI trial. Int J Cardiol. [Epub December 3, 2012.]
70. Brito LA, Chandrasekhar S, Little SR, Amiji MM. Non-viral eNOS gene delivery and transfection with stents for the treatment of restenosis. Biomed Eng Online. 2010;9:56.

71. Sharif F, Hynes SO, McCullagh KJ, et al. Gene-eluting stents: non-viral, liposome-based gene delivery of eNOS to the blood vessel wall in vivo results in enhanced endothelialization but does not reduce restenosis in a hypercholesterolemic model. Gene Ther. 2012;19:321-328.

72. Indermuehle A, Bahl R, Lansky AJ, et al. Drug-eluting balloon angioplasty for in-stent restenosis: a systematic review and metaanalysis of randomised controlled trials. Heart. 2013;99:327-333.

73. Latib A, Colombo A, Castriota F, et al. A randomized multicenter study comparing a paclitaxel drug-eluting balloon with a paclitaxel-eluting stent in small coronary vessels: the BELLO (Balloon Elution and Late Loss Optimization) study. J Am Coll Cardiol. 2012;60:2473-2480.

74. Cortese B, Micheli A, Picchi A, et al. Paclitaxel-coated balloon versus drug-eluting stent during PCI of small coronary vessels, a prospective randomised clinical trial. The PICCOLETO study. Heart. 2010;96:1291-1296.

75. Unverdorben M, Kleber FX, Heuer H, et al. Treatment of small coronary arteries with a paclitaxel-coated balloon catheter. Clin Res Cardiol. 2010;99:165-174.

76. Hamm C. PEPCAD III: a randomised trial comparing a pacitaxel-coated balloon-stent system. American Heart Association Scientific Sessions; November 14-18, 2009; Orlando, FL, USA.

77. Werner G. PEPCAD-CTO: A prospective non-randomised study of paclitaxel eluting balloons after BMS placement in successfully recanalised chronic total occlusions. Transcatheter Cardiovascular Therapeutics; September 21-25, 2010; Washington DC, DC, USA.

78. Ormiston JA, Lefèvre T, Grube E, Allocco DJ, Dawkins KD. First human use of the TAXUS Petal paclitaxel-eluting bifurcation stent. EuroIntervention. 2010;6:46-53.

79. Unverdorben M, Vallbracht C, Cremers B, et al. Paclitaxel-coated balloon catheter versus paclitaxel-coated stent for the treatment of coronary in-stent restenosis. Circulation. 2009;119:2986-2994.

80. Byrne RA, Neumann F-J, Mehilli J, et al; ISAR-DESIRE 3 investigators. Paclitaxel-eluting balloons, paclitaxel-eluting stents, and balloon angioplasty in patients with restenosis after implantation of a drugeluting stent (ISAR-DESIRE 3): a randomised, open-label trial. Lancet. 2012;381:461-467.

81. Rittger H, Brachmann J, Sinha AM, et al. A randomized, multicenter, single-blinded trial comparing paclitaxel-coated balloon angioplasty with plain balloon angioplasty in drug-eluting stent restenosis: the PEPCAD-DES study. J Am Coll Cardiol. 2012;59:1377-1382.

82. Habara S, Mitsudo K, Kadota K, et al. Effectiveness of paclitaxel-eluting balloon catheter in patients with sirolimus-eluting stent restenosis. JACC Cardiovasc Interv. 2011;4:149-154.

83. Scheller B, Clever YP, Kelsch B, et al. Long-term follow-up after treatment of coronary in-stent restenosis with a paclitaxel-coated balloon catheter. JACC Cardiovasc Interv. 2012;5:323-330.

84. Bondesson P, Lagerqvist B, James SK, Olivecrona GK, Venetsanos D, Harnek J. Comparison of two drug-eluting balloons: a report from the SCAAR registry. EuroIntervention. 2012;8:444-449.

\section{Publish your work in this journal}

Research Reports in Clinical Cardiology is an international, peerreviewed, open access journal publishing original research, reports, editorials, reviews and commentaries on all areas of cardiology in the clinic and laboratory. The manuscript management system is completely online and includes a very quick and fair peer-review system.

\section{Dovepress}

Submit your manuscript here: http://www.dovepress.com/research-reports-in-clinical-cardiology-journal 